\title{
Development and Application of Oxysilane Sol-Gel Electrochemical Glucose Biosensors Based on Cobalt Hexacyanoferrate Modified Carbon Film Electrodes
}

\author{
Monica Florescu, ${ }^{\mathrm{a}, \mathrm{b}}$ Madalina Barsan, ${ }^{\mathrm{a}}$ Rasa Pauliukaite, ${ }^{\mathrm{a}}$ Christopher M. A. Brett ${ }^{\mathrm{a} *}$ \\ a Departamento de Quimica, Universidade de Coimbra, 3004-535 Coimbra, Portugal \\ b Department of Physics, Transilvania University of Brasov, 500036 Brasov, Romania \\ *e-mail: brett@ci.uc.pt
}

Received: July 21, 2006

Accepted: September 18, 2006

\begin{abstract}
The evaluation and characterization of a new glucose oxidase (GOx) electrochemical enzyme biosensors on a carbon film electrode support and using two types of sol-gel precursor mixture for enzyme immobilization was carried out in order to be employed as a short-time-use or as a disposable sensor. Carbon film electrodes were modified with films of $\mathrm{CoHCF}$ mediator by potential cycling. The sol-gel was prepared using a combination of 3-glycidoxypropyltrimethoxysilane (GOPMOS) with methyltrimethoxysilane (MTMOS) or tetraethoxysilane (TEOS).

The best biosensor sensitivity (ca. $\left.139 \mathrm{nA} \mathrm{mM}{ }^{-1}\right)$ and limit of detection $(24 \mu \mathrm{M})$ to glucose was obtained when a combination of GOPMOS with MTMOS sol-gel was used, but for a short linear range $(0-0.2 \mathrm{mM})$ and using a big concentration of immobilized enzyme (ca. 3.5\%). The longest linear range $(0-1 \mathrm{mM})$ was obtained for the biosensor prepared with GOPMOS and TEOS sol-gel but with lower sensitivity $\left(19.7 \mathrm{nA} \mathrm{mM}{ }^{-1}\right)$ and a bigger detection limit $(71 \mu \mathrm{M})$ with a concentration of immobilized enzyme of $1 \%$. The biosensors were used at $0.0 \mathrm{~V}$ vs. SCE with minimal interference from carboxylic acids and phenol; only ascorbate showed a significant interference but this effect was decreased to $3 \%$ by coating with Nafion polymer. The biosensor was successfully applied to the analysis of glucose in wine samples.
\end{abstract}

Keywords: Electrochemical biosensor, Sol-gel, Cobalt hexacyanoferrate mediator, Glucose oxidase enzyme, Wine

DOI: 10.1002/elan.200603714

\section{Introduction}

The development of easy-to-use and robust biosensors is an important challenge in areas of application such as medical, environmental, agricultural and biotechnological [1-7]. The most widely used amperometric biosensors are based on oxidase enzymes (e.g., glucose oxidase, GOx) that generate $\mathrm{H}_{2} \mathrm{O}_{2}$, the transduction path being the electrochemical oxidation of the hydrogen peroxide formed $[8,9]$. A serious problem that must be overcome for using such biosensors in natural samples is the presence of metabolites or other compounds that represent positive interference due to the fact that they are oxidized/reduced at the same potential as $\mathrm{H}_{2} \mathrm{O}_{2}$. One solution is to utilize an electroactive compound that will act as a redox mediator, decreasing the hydrogen peroxide reduction or oxidation potential to close to $0.0 \mathrm{~V}[10]$.

Transition metal hexacyanoferrates (MHCF) are becoming widely used redox mediators for biosensors because of their mixed-valence cluster organization that can transfer electrons during reduction and oxidation processes $[11,12]$. Prussian blue (ferric ferrocyanide) has been the most widely used of the metal hexacyanoferrates to develop enzyme redox mediators [5]. Besides Prussian blue, other metal hexacyanoferrates investigated for hydrogen peroxide detection in biosensors are CuHCF [13], NiHCF [14] and CoHCF [15]. CoHCF-redox mediated electrochemical biosensors have been used for the catalytic determination of glutathione [16], dopamine [17] and morphine [18].

In our previous studies a CoHCF-film supported on a carbon film electrode [21] has been characterized [19] and used in a biosensor with cross-linked GOx, having excellent glucose detection limits in the micromolar range [20]. These carbon film electrodes have a wider potential range than many other forms of carbon, especially after electrochemical pretreatment [22]. Such electrodes are inexpensive and offer an easy way for developing sensors and biosensors [23-26].

The biosensor stability and analytical performance depends on both the immobilization process, using physical or chemical procedures, and the matrix used for immobilization of the enzyme. Good results were obtained in our previous investigations using cross-linking with glutaraldehyde [23-26] and using sol-gel [13] as immobilization methods for GOx.

Sol-gel encapsulation of biomaterials and organic complexes has recently undergone important developments, sol-gel being an interesting and versatile way to prepare 
modified electrodes and biosensors [27, 28]. Through careful selection of sol-gel precursors and additives, these materials can be designed to produce useful, robust sensors. Sol-gel-derived glasses have emerged in recent years as a new class of material well suited to the immobilization of biomolecules such as enzymes and for these reasons have been widely applied to the development of electrochemical biosensors [29-36]. An enzyme can be immobilized by building the porous gel network around each enzyme macromolecule by encapsulation that does not involve formation of any covalent bond between the support and the enzyme, thus allowing the preservation of enzyme activity [35]. The hydrophilic-hydrophobic nature of the silica gels ensures good compatibility in their application to biosensors [37].

The present study deals with the development, evaluation and characterization of a sol-gel encapsulated glucose oxidase (GOx) electrochemical biosensor, based on a carbon film electrode support and with a bilayer configuration. Carbon film electrodes were first modified by deposition of cobalt hexacyanoferrate using cyclic voltammetry, as described previously [20]. The second layer consisted of the sol-gel containing GOx enzyme, which was prepared using a combination of 3-glycidoxypropyltrimethoxysilane (GOPMOS) with either methyltrimethoxysilane (MTMOS) or tetraethoxysilane (TEOS). The solgel was prepared without the usual addition of alcohol to the precursors and the ethanol formed during precursor hydrolysis was removed by heating of the sol-gel mixture $[13,38,39]$. The proposed biosensor exhibited good analytical performance in the quantification of glucose.

\section{Experimental}

\subsection{Chemicals}

Three different trioxysilanes were used for enzyme encapsulation: tetraethoxysilane (TEOS) from Fluka (Switzerland), 3-glycidoxypropyltrimethoxysilane (GOPMOS) and methyltrimethoxysilane (MTMOS) from Aldrich (Germany). Glucose oxidase (GOx, EC 1.1.3.4, II-type from Aspergillus niger, 35600 units $/ \mathrm{mg})$ and $\alpha-\mathrm{D}(+)$-glucose were from Sigma (Germany). Nafion 5\% (v/v) was from SigmaAldrich, UK. Potassium hexacyanoferrate(III) $\left(\mathrm{K}_{3} \mathrm{Fe}(\mathrm{CN})_{6}\right)$, $\mathrm{CoCl}_{2} 6 \mathrm{H}_{2} \mathrm{O}$ were obtained from Merck (Germany); all other inorganic reagents were of analytical grade.

All solutions were prepared using Millipore Milli-Q nanopure water (resistivity $>18 \mathrm{M} \Omega \mathrm{cm}$ ). The supporting electrolyte for sensor evaluation was phosphate buffer saline (PBS) ( $0.1 \mathrm{M}$ phosphate buffer $+0.05 \mathrm{M} \mathrm{NaCl})$, $\mathrm{pH}$ 7.0. Glucose standard solutions were prepared by dilution of a $100 \mathrm{mM} \alpha-\mathrm{D}(+)$-glucose stock solution prepared in water. The stock solution was prepared $24 \mathrm{~h}$ before use to establish the anomeric equilibrium between $\alpha$ and $\beta$ forms of D-glucose; it was kept in the refrigerator at $+4{ }^{\circ} \mathrm{C}$ and used within a week. Hydrogen peroxide solutions were calibrated by titration with acidified $\mathrm{KMnO}_{4}$ solution.
Experiments were carried out at room temperature $(25 \pm$ $\left.1{ }^{\circ} \mathrm{C}\right)$.

\subsection{Preparation of Carbon Film Electrode}

Electrodes were prepared from carbon film electrical resistors (2 $\Omega$ nominal resistance), as described in [21]. Briefly, these electrical resistors are fabricated by pyrolytic deposition of carbon at $1100^{\circ} \mathrm{C}$ in a nitrogen atmosphere containing a small amount of methane onto ceramic cylinders of length $0.60 \mathrm{~cm}$ and external diameter $0.15 \mathrm{~cm}$. Tight fitting metal caps attached to external connecting wires are then press fitted to each end.

The metal cap plus conducting wire was removed from one of the ends of a resistor, the remaining conducting wire sheathed in plastic insulation up to the respective cap and the cap and plastic contact area carefully covered with epoxy resin so that only the carbon film would be exposed to solution. After this assembly, the exposed electrode geometric area was ca. $0.20 \mathrm{~cm}^{2}$.

\subsection{Electrochemical Measurements}

Measurements were made in a one-compartment cell containing the modified carbon film working electrode, a platinum foil auxiliary electrode and a saturated calomel electrode (SCE) as reference. Voltammetric and amperometric experiments were carried out using CV-50W Voltammetric Analyzer from Bioanalytical Systems, West Lafayette, Indiana, USA, controlled by BAS CV-2.1 software.

\subsection{Electrochemical Modification of Carbon Film with Cobalt(II)-hexacyanoferrate}

The carbon film electrodes were modified by electrochemical deposition of cobalt(II)-hexacyanoferrate (CoHCF). This was done by cycling the applied potential 15 times between 0.0 and $+0.9 \mathrm{~V}$ at a scan rate of $50 \mathrm{mV} \mathrm{s}^{-1}$ in a freshly prepared solution containing $0.5 \mathrm{mM} \mathrm{CoCl}_{2}$, $0.25 \mathrm{mM} \mathrm{K}_{3} \mathrm{Fe}(\mathrm{CN})_{6}$ and $50 \mathrm{mM} \mathrm{NaCl}$ at $\mathrm{pH} 3.0(\mathrm{pH}$ adjusted with $\mathrm{HCl}$ ) with solution agitation by slow mechanical stirring. The CoHCF film modified electrodes were stabilized for 1 hour in $0.05 \mathrm{M} \mathrm{NaCl}, \mathrm{pH} 3.0$ and left to dry at room temperature. Modification of the electrodes was always carried out employing the same, identical solution composition in order to obtain reproducible results.

\subsection{Enzyme Immobilization}

In the optimized procedure, sol-gel solution was prepared by mixing oxysilanes and water in the ratios: GOPMOS: TEOS: $\mathrm{H}_{2} \mathrm{O}-130: 70: 600 \mu \mathrm{L}$; and GOPMOS:MTMOS: $\mathrm{H}_{2} \mathrm{O}-150: 70: 620 \mu \mathrm{L}$. A volume of $2 \mu \mathrm{L}$ of $1 \mathrm{M} \mathrm{HCl}$ 
solution was added to each mixture to promote hydrolysis. The mixtures obtained were intensively stirred for a few minutes and then sonicated for $15 \mathrm{~min}$. Following this, the mixtures were heated in a hot air stream $\left(\mathrm{ca} .70^{\circ} \mathrm{C}\right.$ ) to evaporate the alcohol formed during hydrolysis of the oxysilanes until the solutions lost $40 \%$ of their volume [39]; they were left for $10 \mathrm{~min}$ at room temperature to cool down and neutralized to $\mathrm{pH} 7.0$ by addition of $0.1 \mathrm{M} \mathrm{NaOH}$. Then $50 \mu \mathrm{L}$ of each solution was carefully mixed with $15 \mu \mathrm{L}$ of $4-$ $15 \%$ GOx solution in $0.1 \mathrm{M}$ PBS solution $\mathrm{pH}$ 7.0. Following this, CoHCF-coated carbon film electrodes were immersed in the sol-gel-enzyme solutions for $5 \mathrm{~min}$, removed and then left for sol-gel formation at $+4{ }^{\circ} \mathrm{C}$ for 3 days. Electrodes were stored in PBS buffer electrolyte at $+4^{\circ} \mathrm{C}$ when not in use.

\subsection{Analysis of Wine Samples}

For analysis of wine, samples were diluted 10 times with 0.1 M PBS, pH 6.94, and the wine-containing solution was spiked three times with $0.1 \mathrm{mM}$ aliquots of standard glucose solution to construct the analytical curve using the standard addition method.

Independent analysis of glucose concentrations was done using the standard spectrophotometric enzyme assay kit [40] (Cat 0139 106, Boehringer, Mannheim).

\section{Results and Discussion}

\subsection{Preparation of Sol-Gel Films on CoHCF-Modified Electrodes}

The CoHCF layer was first deposited on the electrode surface and a layer of a sol-gel with entrapped enzyme was then deposited on top of the mediator layer.

The modification of carbon film electrodes by $\mathrm{CoHCF}$ was carried out by cyclic voltammetry, and voltammograms were continuously recorded. Figure 1 illustrates the formation and growth of the CoHCF film onto the carbon film electrode. The modified electrode formed during the above cycling was kept in $0.05 \mathrm{M} \mathrm{NaCl}$ electrolyte, $\mathrm{pH} 3.0$, in this way yielding a stable $\mathrm{CV}$ response over time. The working conditions were kept as previously [20].

The sol-gel enzyme mixture was deposited onto the surface of the CoHCF-modified carbon film electrode by dipping the electrode into sol-gel solution, as described in Section 2.5, using optimized sol-gel formation conditions [13]. Concerning the three precursors used here and by studying the sol-gel morphology using AFM, it was observed that MTMOS has many relatively large pores (ca. $100 \mathrm{~nm}$ ) and the enzyme may be leaching out. The GOPMOS surface has smaller pores $(<30 \mathrm{~nm})$ that do not allow enzyme leaching to occur easily. It was observed that TEOS does not form a solid film on hydrophobic surfaces, just some sol-gel islands. Nevertheless, if higher GOPMOS or TEOS concentrations are used, the coverage appears

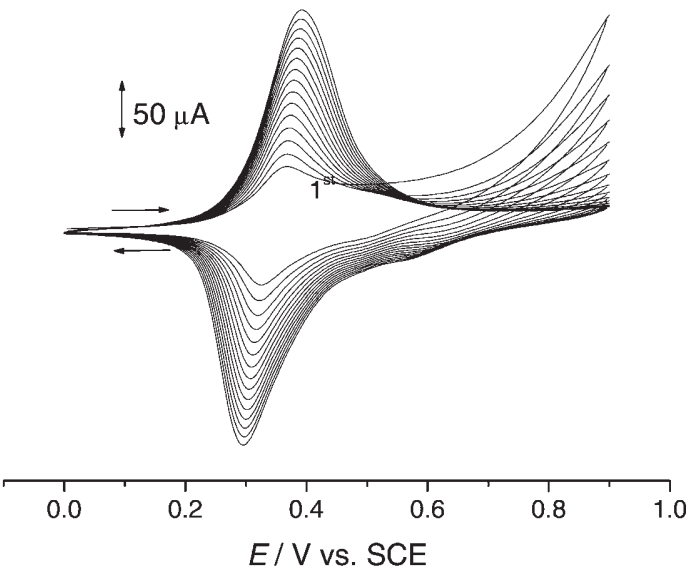

Fig. 1. Cyclic voltammograms showing the continuous growth of CoHCF on carbon film electrode. Solution composition: $0.5 \mathrm{mM}$ $\mathrm{CoCl}_{2}, 0.25 \mathrm{mM} \mathrm{K}_{3} \mathrm{Fe}(\mathrm{CN})_{6}, 50 \mathrm{mM} \mathrm{NaCl}$; pH 3.0 Scan rate 50 $\mathrm{mV} \mathrm{s}^{-1}$.

almost complete with very low porosity but, at the same time, there is poor contact between enzyme and substrate [13]. These results demonstrated the hydrophobic character of GOPMOS compared with the less hydrophobic MTMOS and hydrophilic TEOS [32].

Since the highest sensitivity was observed with the biosensor with encapsulated GOx using GOPMOS as sol-gel precursor and the highest limit of detection with the longer linear range were observed at the widely used TEOS based sol-gel [13], the combination of GOPMOS and TEOS precursors was studied and compared with GOPMOS plus MTMOS in the development of glucoseoxidase biosensors. Different proportions of each precursor have been tested [41] and the optimum composition was found to be GOPMOS : TEOS: $\mathrm{H}_{2} \mathrm{O}-130: 70: 600 \mu \mathrm{L}$ and GOPMOS : MTMOS: $\mathrm{H}_{2} \mathrm{O}-150: 70: 620 \mu \mathrm{L}$. These compositions will be abbreviated to GTand GM, respectively, in the text that follows.

Silica gels with a texture closer to other types of polymeric gels are obtained when the hydrolysis rate is faster than the condensation rate, which requires adding an acid catalyst as described in the experimental section. The alcohol released during the hydrolysis reaction can deactivate the enzyme and for this reason the alcohol was eliminated after hydrolysis by evaporation in a hot air stream $\left(\mathrm{ca} .70^{\circ} \mathrm{C}\right.$ ) until the solutions lost $40 \%$ of their volume. Prior to adding the enzyme in buffered solution, the gels were left $10 \mathrm{~min}$ at room temperature and neutralized to $\mathrm{pH} 7.0$ before adding the enzyme in PBS solution. The concentration of the entrapped enzyme has a big influence on biosensor response, since it has been observed that an increase in the concentration of some entrapped enzymes can result in a marked decrease in specific activity that can form aggregates at higher concentrations [34]. For this reason different concentrations of enzyme in PBS solution were used: $4 \%$, $10 \%$ and $15 \%$, that correspond to concentrations of approximately $1.0 \%, 2.3 \%$ and $3.5 \%$ in the resulting dry gel on the electrode surface. 
As previously noted [41] as well as in this work, when the sol-gel modified electrode was kept under wet conditions, it maintained its initial properties and permitted good mobility of the analyte to the enzyme and diffusion of the products to the redox mediator layer. Therefore, the biosensors were kept in $0.1 \mathrm{M}$ PBS solution, $\mathrm{pH} 7.0$, at $4{ }^{\circ} \mathrm{C}$ when not in use.

\subsection{Electrochemical Characterization of Sol-Gel Biosensor with CoHCF Film}

CoHCF has a rather low stability at neutral $\mathrm{pH}$, but the solgel layer was able to stabilize it. Deposition of sol-gel on the mediator film changed the electrochemical behavior of CoHCF. The redox mediator peak current decreases significantly in the case of both sol-gel mixtures tested. The redox peaks of CoHCFalmost disappeared in the sensor after GM film formation (Fig. 2A). Addition of $10 \mathrm{mM}$ $\mathrm{H}_{2} \mathrm{O}_{2}$ to the PBS solution increases the oxidation current slightly in the positive potential region but decreases the CoHCF reduction peak current, as seen in Figure 2A (solid curve). However, when the other sol-gel mixture, GT, was used for the sensor preparation, the resulting redox peaks of CoHCF film were still visible although the current was significantly smaller. The shape of the redox peaks remained almost the same as at bare CoHCF but the peak separation became a little larger, so that the reversibility of the mediator was less than without sol-gel (Fig. 2B).

The same sequence of the electrochemical characterization experiments was performed with CoHCF-based biosensors with enzyme entrapped in the sol-gel layer. The electrochemical behavior of biosensors was observed to be similar to that without enzyme, as is demonstrated in Figure 3.

The sensor was applied to hydrogen peroxide detection using amperometry at constant applied potential. The applied potential at $\mathrm{CoHCF}$ modified carbon films was $0.0 \mathrm{~V}$ vs. SCE in $0.1 \mathrm{M}$ PBS solution, $\mathrm{pH}$ 6.94, that was found optimal for $\mathrm{H}_{2} \mathrm{O}_{2}$ and glucose detection in previous work [20], and also ensures small interference effects when the electrode is used in natural and complex sample matrices. Both GT and GM sensors exhibited similar sensitivity to $\mathrm{H}_{2} \mathrm{O}_{2}$.

\subsection{Glucose Detection with Sol-Gel Biosensors}

Glucose detection was done with both type of sol-gel mixture CoHCF-mediated biosensors, and data from analysis of the calibration plots are given in Table 1 . The best sensitivity of the biosensors of $138.8 \mathrm{nA} \mathrm{mM}^{-1}$ and a limit of detection of $24 \mu \mathrm{M}$ was obtained when GM sol-gel was used, but it exhibited a short linear range $0-0.2 \mathrm{mM}$ and only using a rather large concentration of immobilized enzyme $(3.46 \%)$. The longer linear range $(0-1 \mathrm{mM})$ was observed for the biosensor prepared with GT sol-gel, but with lower sensitivity and higher limit of detection

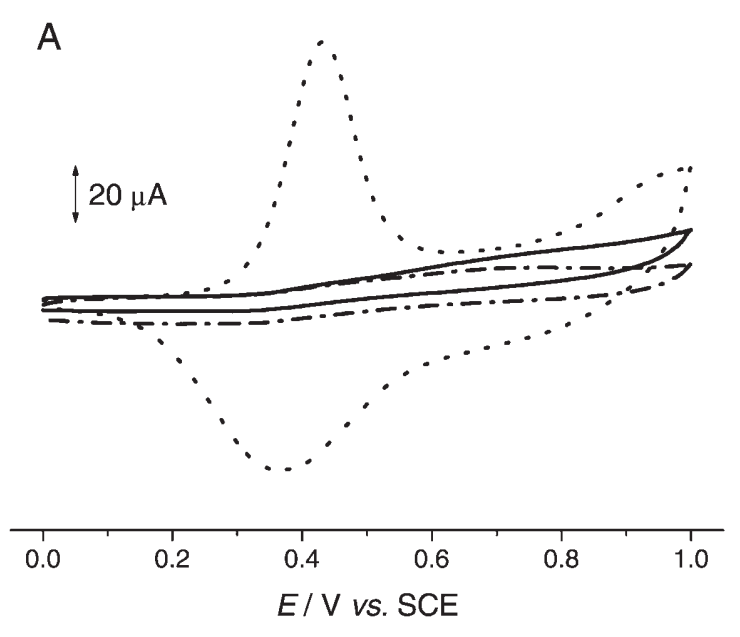

B

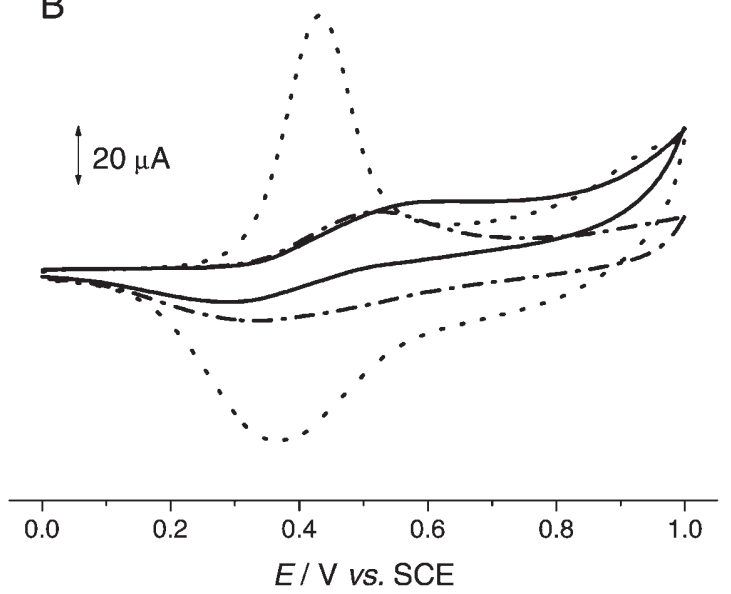

Fig. 2. Cyclic voltammograms in $0.1 \mathrm{M}$ PBS, pH 6.94, of $\mathrm{CoHCF}(\cdots \cdots)$, sol-gel film applied on top of CoHCF mediator layer (-- ) and after addition of $10 \mathrm{mM} \mathrm{H}_{2} \mathrm{O}_{2}$ to the buffer solution (-). Sol-gel precursors: A) GOPMOS-MTMOS; B) GOPMOS-TEOS. Scan rate $50 \mathrm{mV} \mathrm{s}^{-1}$.

$(71.4 \mu \mathrm{M})$ for a concentration of immobilized enzyme of $1 \%$ (Fig. 4). Use of concentrations of immobilized enzyme higher than $3.46 \%$ did not show any improvement in the analytical properties (results not shown).

These results can be explained taking into account that the concentration of the encapsulated enzyme has a big influence on its activity. The accessibility of analyte to the enzyme is determined largely by the pore size and the electrostatics of the material, which can be tuned by various methods including variation of precursors, sol - gel synthesis conditions, silane:solvent ratio, aging conditions and so on. For GM-based biosensors the combination of GOPMOS with MTMOS leads to a pore structure of a dry gel that is favorable for the higher concentration of immobilized enzyme. These biosensors present a high sensitivity but the linear response range is short, caused by the big accessibility of the glucose to the entrapped enzyme through the pores of the gel obtained by the combination of two 

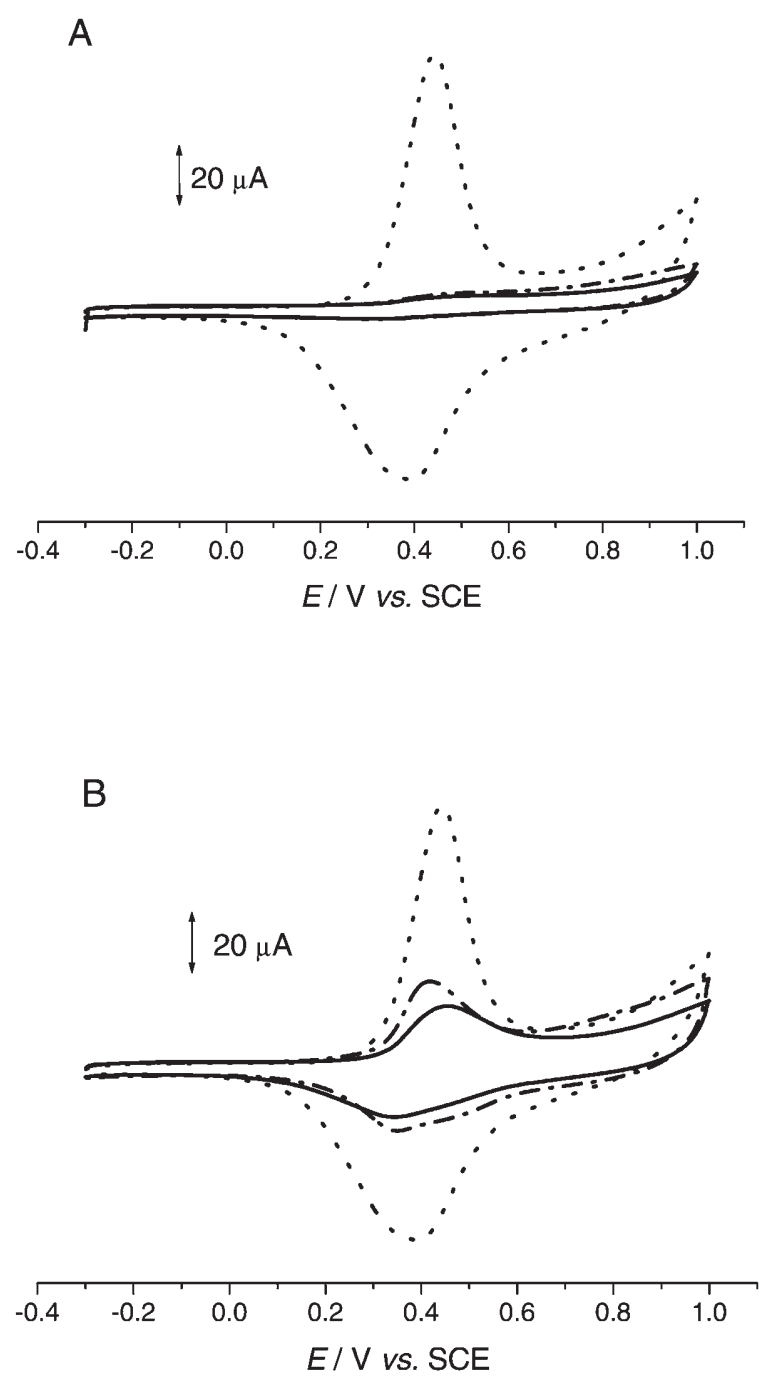

Fig. 3. Cyclic voltammograms in $0.1 \mathrm{M}$ PBS, pH 6.94, of CoHCF $(\cdots \cdots)$, enzyme sol-gel film applied on top of CoHCF mediator layer $(-\cdot \cdot-)$ and after addition of $5 \mathrm{mM}$ glucose to the buffer solution (-). Sol-gel precursors: A) GOPMOS-MTMOS; B) GOPMOS-TEOS. Scan rate $50 \mathrm{mV} \mathrm{s}^{-1}$.

hydrophobic precursors with different extents of hydrophobicity. According to the results obtained, the pore dimensions of the dry gel seem to be big enough to permit easy access of the glucose to the enzyme and to its active sites. Using a high concentration of the enzyme solution also ensures the presence of a sufficient quantity of immobilized

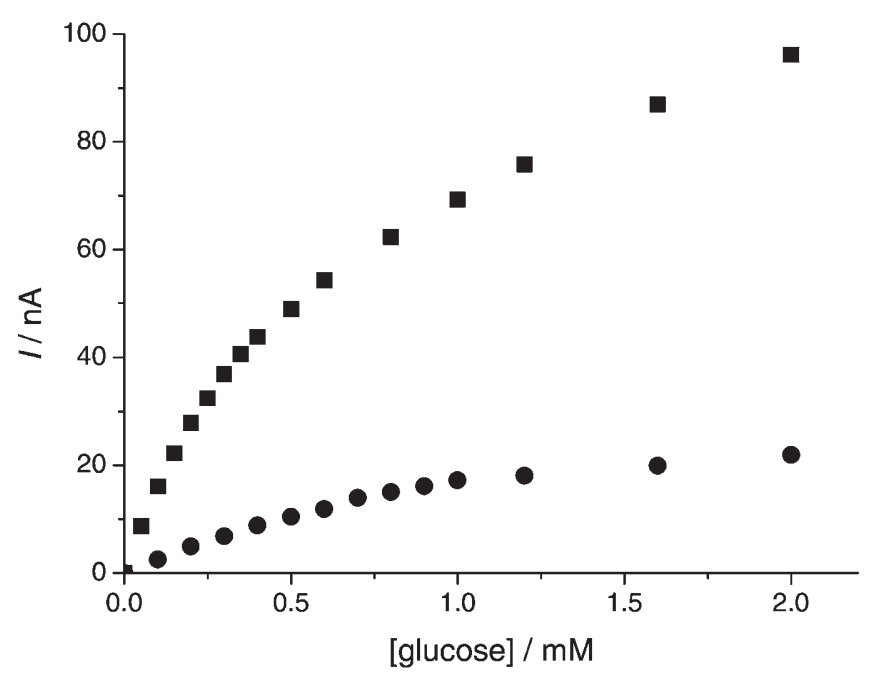

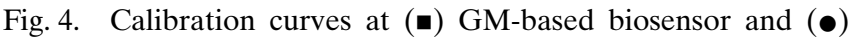
GT-based biosensor at applied potential $0.0 \mathrm{~V}$ vs. SCE for successive additions of glucose to $0.1 \mathrm{M} \mathrm{PBS} \mathrm{pH} \mathrm{6.94.}$

enzyme on the biosensor surface, even allowing for enzyme leakage due to the big dimensions of the pores.

In the case of GT-based biosensors the glucose reaches the immobilized enzyme over a longer time period that can be caused by the small dimensions of the dry gel pores due to the combination of the hydrophobic GOPMOS with the hydrophilic TEOS. In this case the enzyme substrate has more difficulty in reaching the enzyme, the active site of which can be buried in a nonaccessible way inside the nanocages where the enzyme is immobilized.

The reproducibility of three different biosensors was tested and a RSD of 5.1\% for GM-based biosensors and $4.3 \%$ for GM-based biosensors was obtained. Results of testing newly prepared biosensors after different time intervals showed for both type of biosensors that the sensitivity values increased during $24 \mathrm{~h}$ after the first testing, which can be due to reorganization of the sol-gel network and has been noted previously [39], and then began to decrease, see Figure 5. The variation in sensitivity and limit of detection of GT-based biosensors (with 3.46\% enzyme) for 1 month testing is shown in Figure 5. A decrease of the sensitivity, until $23 \%$ of the initial value, is accompanied by an increase in detection limit to $70 \mu \mathrm{M}$. Nevertheless, this loss of sensitivity is not a problem for short-term use sensors and was also found not to be a drawback in the measurement

Table 1. Data from calibration plots of CoHCF-mediated glucose biosensors with GM and GT sol-gel precursor mixtures.

\begin{tabular}{lllllll}
\hline Sol - gel & [Enzyme] $(\%)$ & Sensitivity $\left(\mathrm{nA} \mathrm{mM}^{-1}\right)$ & Intercept $(\mathrm{nA})$ & $L O D(\mu \mathrm{M})$ & Linear range $(\mathrm{mM})$ & $K_{\mathrm{M}}(\mathrm{mM})$ \\
\hline $\mathrm{GM}$ & 1.0 & $47.6 \pm 0.3$ & $0.64 \pm 0.70$ & 59 & $0-0.4$ & 0.97 \\
& 2.3 & $39.7 \pm 0.2$ & $0.51 \pm 0.30$ & 34 & $0-0.4$ & 1.28 \\
$\mathrm{GT}$ & 3.5 & $138.8 \pm 0.1$ & $1.09 \pm 0.90$ & 24 & $0-0.2$ & 0.59 \\
& 1.0 & $19.7 \pm 0.1$ & $0.56 \pm 0.30$ & 71 & $0-1.0$ & 0.62 \\
& 2.3 & $29.9 \pm 0.1$ & $0.33 \pm 0.20$ & 30 & $0-0.25$ & 0.79 \\
\hline
\end{tabular}




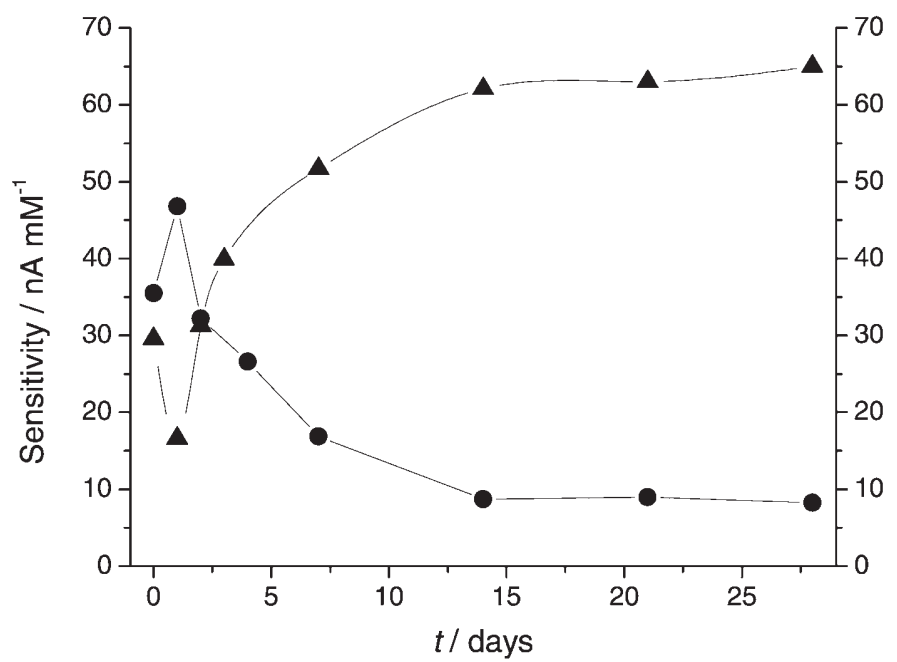

Fig. 5. The variation in sensitivity $(\bullet)$ and limit of detection ( $\mathbf{\bullet})$ with time of GT-based biosensors at applied potential $0.0 \mathrm{~V}$ vs. SCE for glucose in $0.1 \mathrm{M}$ PBS $\mathrm{pH} 6.94$.

of glucose using the standard addition method with enzymes, as will be seen below.

Since it was desired to apply the sensor to the analysis of glucose in wines, a study of interferences from compounds usually present in wine was also performed: the results are shown in Table 2. The results are slightly different for the two types of biosensors, the GT-based biosensors being less affected by the presence of interfering compound, especially of ascorbic acid. Fructose, the main sugar usually present in wine beside glucose, did not interfere; from the principal acids, ascorbic acid presented an interference, which decreased the response to glucose and a very small extent appears for acetic acid. Phenolic compounds present in the wine, such as phenol, also led to a small interference. However, such interferences should not play a significant role in the determination of glucose by the standard addition method in wine; moreover, the interfering compounds are present at small concentrations compare with that of glucose.

Negatively charged polymer film-modified electrodes have been used to suppress the interference of ascorbic acid with the determination of different biological compounds in real samples [42,43]. An anionic polymer, Nafion, can be used, which repels ascorbate and other negatively charged interferents, but does not affect neutral glucose molecules $[44,45]$. Although the Nafion coating introduced the desired specificity, it has some disadvantages, for example that a relatively thick film is required which increases the response time of the sensor. Kristensen et al. [46] observed that when the electrodes were soaked in Nafion solution for a longer time (10 min) and then allowed to dry, the humidity at the electrode appears to affect the $\sum_{\text {I }}$ rate of solvent evaporation. Another approach is rapidly (0.1 s) dipping the electrode into the Nafion solution many times and leaving it to dry for a longer time.

We chose the second approach, rapidly immersing the CoHCF-modified carbon film electrode in Nafion solution ten times with approximately $2 \mathrm{~s}$ between dips, followed by $10 \mathrm{~min}$ under the heat gun. After this procedure, the electrodes were allowed to dry at room temperature overnight and enzyme immobilization with the sol-gel procedure was then carried out. Repeating the interference studies for ascorbic acid (the main interfering compound) with the Nafion film between the CoHCF and enzyme layers, reduced the interference effect from 12 to $3 \%$.

\subsection{Glucose Detection with Sol-Gel Biosensors in Wine}

In order to test the applicability of the sensors to foods and beverages, several commercial wines were analyzed by the standard addition method. The GT-based biosensor with $3.5 \%$ immobilized enzyme, which showed the best performance in the previous experiments, was chosen for these measurements. The wine samples were diluted 10 times with 0.1 M PBS, pH 6.94, and the wine-containing solution was spiked three times with $0.1 \mathrm{mM}$ aliquots of standard glucose solution. Results obtained from three repetitive measurements are shown in Table 3. The data obtained are in good agreement with the colorimetric enzyme test kit measurements based on the standard spectrophotometric method

Table 3. Results of analysis of wine samples using the GT sol gelbased biosensor and the standard spectrophotometric enzyme assay.

\begin{tabular}{lll}
\hline Sample & \multicolumn{2}{l}{ Glucose concentration $(\mathrm{mM})$} \\
\cline { 2 - 3 } & GT biosensor & Reference [a] \\
\hline White wine 1 & $1.9 \pm 0.02$ & $1.7 \pm 0.001$ \\
White wine 2 & $2.1 \pm 0.2$ & $2.2 \pm 0.01$ \\
Red wine 1 & $1.6 \pm 0.1$ & $1.4 \pm 0.001$ \\
Red wine 2 & $1.4 \pm 0.1$ & $1.3 \pm 0.01$ \\
\hline
\end{tabular}

[a] Colorimetric method with enzymatic test kit

Table 2. Results of study of interferences to glucose response at GM and GT sol-gel based biosensors.

\begin{tabular}{llcr}
\hline Compound & Glucose: interfering compound & Relative response (\%) \\
\cline { 3 - 4 } & & GM biosensor & GT biosensor \\
\hline Fructose & $1: 3$ & 100 & 100 \\
Acetic acid & $1: 3$ & 103 & 102 \\
Tartaric acid & $1: 3$ & 100 & 100 \\
Phenol & $1: 3$ & 98 & 99 \\
Ascorbic acid & $1: 1$ & 73 & 88 \\
\hline
\end{tabular}


[41]. This augurs well for application of the GT-based biosensor for glucose monitoring in grape must during the fermentation process as well as in wines and other foods.

\section{Conclusions}

Carbon film electrodes have been modified with cobalt hexacyanoferrate redox mediator films followed by enzyme immobilization in a sol-gel layer from a sol-gel precursor mixture and successfully used as biosensors at low applied potential. The sol-gel was prepared using a mixture of 3glycidoxypropyl-trimethoxysilane with either methyltrimethoxysilane (GM) or tetraethoxysilane (GT). The changes in proportions of hydrophilic and hydrophobic surface groups of sol-gel precursors influence the performance of gel-based biosensors due to the internal structure of dry gel that can affect the concentration and the activity of immobilized enzyme on the biosensor surface. Such biosensors were used to determine glucose concentrations down to the micromolar level.

The best electroanalytical properties were exhibited by the CoHCF/GT biosensor operating at $+0.0 \mathrm{~V}$ vs. SCE, thus diminishing the influence of interfering compounds such as other monosaccharides, phenols and carboxylic acids. The linear range at GT biosensor with $3.5 \%$ enzyme immobilized was $0-0.5 \mathrm{mM}$, with a limit of detection of $46 \mu \mathrm{M}$. The sensor was successfully used to determine the glucose concentration in model solutions and in wines.

\section{Acknowledgements}

Financial support from European Project HPRN-CT-200200186 (Novtech) and Fundação para a Ciência e Tecnologia (FCT), ICEMS (Research Unit 103), Portugal are gratefully acknowledged. Prof. H. D. Liess is thanked for the gift of the electrical resistors.

\section{References}

[1] G. G. Guilbault, G. Wagner, Biosensors in Food Analysis, Marcel Dekker, New York 1994.

[2] W. Bourgeois, J. E. Burgess, R. M.Stultz, J. Chem. Technol. Biotechnol. 2001, 76, 337.

[3] D. H. Yu, B. Blankert, J. C. Viré, J. M. Kaufmann, Anal. Lett. 2005, 38, 1687.

[4] A. Amine, H. Mohammadi, I. Bourais, G. Palleschi, Biosens. Bioelectron. 2006, 21, 1405.

[5] F. Ricci, G. Palleschi, Biosens. Bioelectron. 2005, 21, 389.

[6] I. E. Tothill, Comp. Electron. Agric. 2001, 30, 205.

[7] J. Wang, J. Pharm. Biomed. Analysis 1999, 19, 47.

[8] F. Xu, L. Wang, M. Gao, L. Jin, J. Jin, Talanta 2002, 57, 365.

[9] N. Dimcheva, E. Horozova, Z. Jordanova, Z. Naturforsch. 2002, 57, 705 .
[10] A. Chaubey, B. D. Malhotra, Biosens. Bioelectron. 2002, 17, 441.

[11] N. R. de Tacconi, K. Rajeshwar, R. O. Lezna, Chem. Mater. 2003, 15, 3046.

[12] S. M. Chen, Electrochim. Acta 1998, 43, 3359.

[13] R. Pauliukaite, C. M. A. Brett. Electrochim. Acta 2005, 50, 4973.

[14] P. A. Fiorito, S. I. C. de Torresi, J. Electroanal. Chem. 2005, $581,31$.

[15] M. S. Lin, Y. C. Wu, B. I. Jan, Biotechnol. Bioeng. 1999, 62, 56.

[16] D. R. Shankaran, S. S. Narayanan, Bull. Chem. Soc. Jpn. 2002, 75, 501.

[17] Z. Xun, C. Cai, W. Xing, T. Lu, J. Electroanal. Chem. 2003, $545,19$.

[18] F. Xu, M. Gao, L. Wang, T. Zhou, L. Jin, J. Jin, Talanta 2002 , $58,427$.

[19] R. Pauliukaite, M. Florescu, C. M. A. Brett, J. Solid State Electrochem. 2005, 9, 354.

[20] M. Florescu, C. M. A. Brett, Anal. Lett. 2004, 37, 871.

[21] C. M. A. Brett, L. Angnes, H. D. Liess, Electroanalysis 2001, 13,765 .

[22] O. M. S. Filipe, C. M.A. Brett, Electroanalysis 2004, 16, 994.

[23] O. M. S. Filipe, C. M. A. Brett, Talanta 2003, 61, 643.

[24] M. Florescu, C. M. A. Brett, Talanta 2005, 65, 306.

[25] M. E. Ghica, C. M.A. Brett, Anal. Lett. 2005, 38, 907.

[26] M. E. Ghica, C. M. A. Brett, Electroanalysis 2006, 18, 748.

[27] L. Rabinovich, O. Lev, Electroanalysis 2001, 13, 265.

[28] A. Walcarius, Electroanalysis 2001, 13, 701.

[29] A. Walcarius, D. Mandler, J. A. Cox, M. Collinson, O. Lev, J. Mat. Chem. 2005, 15, 3663.

[30] S. Dong, X. Chen, Rev. Molec. Biotechnol. 2002, 82, 303.

[31] F. S. Tripathi, V. B. Kandimalla, H. Ju, Sens. Actuators B 2006, 114, 1071.

[32] A. C. Pierre, Biocatal. Biotransform. 2004, 22, 145.

[33] J. Wang, P. V. A. Pamidi, D. S. Park, Anal. Chem. 1996, 68, 2705.

[34] W. Jin, J. D. Brennan, Anal. Chim. Acta 2002, 461, 1.

[35] A. Kumara, R. Malhotra, B. D. Malhotra, S. K. Grover, Anal. Chim. Acta 2000, 414, 43.

[36] B. Prieto-Simon, G. S. Armatas, P. J. Pomonis, C. G. Nanos, M. I. Prodromidis, Chem. Mater. 2004, 16, 1026.

[37] H. El Rassy, P. Buisson, B. Bouali, A. Perrard, A. C. Pierre, Langmuir 2003, 19, 358.

[38] M. L. Ferrer, F. del Monte, D. Levy, Chem. Mater. 2002, 14, 3619.

[39] R. Pauliukaite, C. M. A. Brett, A. M. Chiorcea Paquim, A. M. Oliveira Brett, Electrochim. Acta 2006, 52, 1.

[40] M. M. Barsan, J. Klinčar, M. Batič, C. M.A. Brett, Talanta, in press, DOI: 10.1016/j.talanta.2006.08.032.

[41] D. Avnir, S. Braun, O. Lev, M. Ottolenghi, Chem. Mater. 1994, 6, 1605.

[42] H. Zhao, Y. Zhang, Z. Yuan, Anal. Chim. Acta 2001, 441, 117.

[43] J.-M. Zen, W.-M. Wang, G. Ilangovan, Anal. Chim. Acta 1998, $372,315$.

[44] S. Alpat, S. K. Alpat, A. Telefoncu, Anal. Bioanal. Chem. 2005, 383, 695.

[45] E. W. Kristensen, W. G. Kuhr, R. M. Wightman, Anal. Chem. 1987, 59, 1752.

[46] F. H. Schmidt, Klin. Wochenschrift 1961, 39, 1244. 